\title{
GAMBARAN PENGETAHUAN IBU TENTANG PENTINGNYA PEMBERIAN IMUNISASI BOOSTER PADA BALITA DI KLINIK SALLY TAHUN 2019
}

\author{
Merlina Sinabariba \\ Staff Pengajar STIKes Santa Elisabeth Medan \\ Email : merlina.sinabariba@yahoo.com
}

\begin{abstract}
Background : Infants healthycan be influenced by the environment in which infants are raised and the immunization they get is also important to do booster immunization at the age of 24 months. When children at Baduta agethey beg in the second stage of immunization which is known as advanced immunization or immunization of Deuteronomy (Booster). Booster is important for boosting the immune response to vaccines which have decreased with age. If no booster is carried out, children are at risk of being unprotected when exposed to diseases that can be prevented, such as an outbreak of diphtheria.

Goals : This study aims to obtain an overview of maternal knowledge about the importance of booster immunization in infants at Sally clinic 2019.The type of research is descriptive with accidental sampling techniques and data collection methods, namely primary data.

Result : The results of this study indicate that from 30 respondents, having good knowledge are 8 people (26.7\%), enough knowledge are 21 people (70.0\%), and those with less knowledge amounted is 1 person (3.3\%).Mother's knowledge of the importance of booster immunization in toddlers at Sally clinic 2019 is largely knowledgeable.

Conculsion : Good information from health workers can increase maternal knowledge about booster immunization in children. Health workers are expected to be able to inform mothers, to be advised to do Booster immunization if the child has complete immunization, to increase immunity to the child's body.
\end{abstract}

\section{PENDAHULUAN}

Pengetahuan (knowledge) adalah hasil tahu dari manusia, yang sekedar menjawab pertanyaan "what", misalnya apa air, apa manusia, apa alam, dan sebainya. Sedangkan ilmu (science) bukan sekedar menjawab "why" dan "how" misalnya mengapa air mendidih bila dipanaskan, mengapa bumi berputar, mengapa manusia bernafas, dan sebagainya (Nursalam, 2014).

Pengetahuan itu sendiri dipengaruhi oleh faktor pendidikan formal. Pengetahuan sangat erat hubungannya dengan pendidikan, dimana diharapkan bahwa dengan pendidikan yang tinggi maka orang tersebut akan semakin luas pula pengetahuannya. Akan tetapi perlu ditekankan, bukan berarti seseorang yang berpendidikan rendah mutlak 
berpengetahuan rendah pula. Hal ini mengingat bahwa peningkatan pengetahuan tidak mutlak diperoleh melalui pendidikan non formal. Imunisasi dengan memasukkan antigen lemah agar merangsang antibodi keluar sehingga tubuh dapat resisten terhadap penyakit tertentu. (Atikah Proverawati, 2017). Imunisasi lanjutan merupakan ulangan imunisasi dasar untuk mempertahankan tingkat kekebalan dan untuk memperpanjang masa perlindungan anak yang sudah mendapatkan imunisasi dasar. Imunisasi ulangan (booster) berarti pemberian kekebalan setelah imunisasi dasar.

Booster penting untuk meningkatkan kembali respon imun terhadap vaksin yang sudah semakin menurun seiring dengan bertambahnya usia. Jika tidak dilakukan booster, anak beresiko tidak terlindungi saat terkena penyakit yang seharusnya bisa dicegah, seperti wabah difteri. Jika sedang ada wabah, imunisasi ulang bisa langsung diberikan, selain melakukan imunisasi sesuai jadwal dan memberikan booster. (Nurazizah, 2012).

Balita anak yang usianya 0 (nol) sampai 59 (lima puluh sembilan) bulan, dimana pada periode umur ini anak tumbuh dan berkembang secara optimal. (Dinkes Kota Medan, 2016). Balita juga disebut anak yang berusia lima tahun kebawah. (Marimbi, 2017). Kesehatan balita dapat dipengaruhi oleh lingkungan tempat balita dibesarkan dan imunisasi yang didapatkannya $0-11$ bulan (imunisasi dasar) dan penting juga untuk di lakukan imunisasi ulang (booster) pada usia 24 bulan. Imunisasi ulang 24 bulan yang imunisasi adalah DPT-HB-HIB, dan campak. Ketika anak di usia Baduta, mulai diberikan imunisasi tahap kedua yang dikenal dengan imunisasi lanjutan atau imunisasi Ulangan (Booster).

Pada umumnya, ibu merupakan sosok yang mempengaruhi lengkapnya pemberian imunisasi pada seorang anak. Status ibu bekerja, sehingga kurang memiliki waktu mengantar anak ke posyandu atau pusat pelayanan kesehatan dianggap menjadi salah satu faktor yang mempengaruhi kelengkapan imunisasi anak. Satu faktor penyebab kegagalan program imunisasi adalah penolakan ibu terhadap imunisasi. Penolakan imunisasi antara lain diakibatkan oleh anggapan salah tentang imunisasi yang berkembang dalam masyarakat, banyak pula orangtua dan kalangan praktisi tertentu khawatir terhadap risiko dari beberapa vaksin. Tanpa Imunisasi, kira-kira 3 dari 100 kelahiran anak akan meninggal karena penyakit campak. Sebanyak 2 dari 100 kelahiran anak akan meninggal karena batuk rejan. Satu dari 100 kelahiran anak akan meninggal karena penyakit tetanus. Dari setiap 200.000 anak, akan menderita penyakit polio. Imunisasi yang dilakukan dengan memberikan vaksin tertentu akan melind ungi anak terhadap penyakit-penyakit tertentu. Pada tahun 2014-2016, terdapat 1.716.659 anak yang belum mendapat imunisasi dan imunisasinya tidak lengkap. Setiap tahun lebih dari 1,4 juta anak di dunia meninggal karena berbagai 
penyakit yang sebenarnya dapat dicegah dengan imunisasi (Riskesdas, 2015). Maka kegiatan imunisasi diperluas menjadi Program Pengembangan Imunisasi (PPI) dalam rangka pencegahan penularan terhadap beberapa Penyakit yang Dapat Dicegah dengan Imunisasi (PD3I), yaitu Tuberkolosis, Difteri, Pertusis, Campak, Polio, Tetanus, Hepatitis-B, serta Pneumonia.

UNICEF menyebut bahwa 19,5 juta anak balita di seluruh dunia belum mendapatkan pelayanan imunisasi lengkap. Akibatnya, 2-3 juta kematian, dan $30 \%$ kematian akibat penyakit yang dapat dicegah dengan imunisasi. Rata-rata di negara ASIA $89 \%$ mendapat imunisasi. Ada sekitar 32.007 kematian per tahun termasuk disebabkan oleh penyakit yang dapat dicegah dengan imunisasi, seperti Difteri, Tetanus, Tubercolosis, Polio, Campak, dan Pertusis.

Menurut Dinkes Sumut tahun

2017 Indikator Program Imunisasi Dasar Lengkap (IDL) di Kota Medan sudah mencapai target $80 \%$ IDL pada bayi dengan hasil 100,7\% IDL pada tahun 2016. Menurut Dinkes Sumut tahun 2017 Indikator Renstra tentang Imunisasi lanjutan tahun 2016 belum mencapai target $40 \%$ anak usia 12-24 bulan yang mendapatkan imunisasi DPT-HBHib lanjutan karena hasil persentase hanya mencapai $39 \%$.

Dikutip dari jurnal ilmu kesehatan tahun 2018, Balitbangkes (2013) menyebutkan bahwa salah satu alasan anak tidak diberikan imunisasi adalah kesibukan pekerjaan orang tua. Berdasarkan hasil penelitian Makamban etal pada tahun 2014 bahwa ibu yang bekerja harus berbagi perhatiannya pada pekerjaan dan mengurus anak yang mengakibatkan pemberian imunisasi tidak menjadi prioritas.

Dikutip dari artikel Jurnal kesehatan global tahun 2018, Hasil penelitian Simangunsing (2011) menunjukkan bahwa sebagian besar tingkatan tindakan responden dalam membawa bayi imunisasi Puskesmas Kolang, Kecamatan Kolang, Kabupaten Tapanuli Tengah berada pada tingkat kategori tidak membawa yaitu sebanyak 44 orang $(100,00 \%)$ dan membawa $0(0,00 \%)$. Alasan Responden tidak membawa bayi karena sibuk kerja sebanyak 30 orang $(68,18 \%)$, dan Responden karena malu sebanyak 5 orang $(11,36 \%)$.

Berdasarkan hasil penelitian Anisah Munawaroh dkk, menunjukkan bahwa pengetahuan responden dengan kategori baik sebesar 39\%, pengetahuan responden dengan kategori kurang baik sebesar 61\%. Dapat disimpulkan bahwa presentase terbesar pengetahuan responden pada pengetahuan kurang baik mengenai imunisasi pentavalen booster. Penelitian Anisah Munawaroh dkk, juga menunjukkan $54 \%$ usia responden pada kategori muda yaitu $<31$ tahun, $51 \%$ dari responden berpendidikan dasar yaitu tidak sekolah, SD, SMP, 59\% responden berstatus pekerjaan tidak bekerja, $61 \%$ responden mempunyai pengetahuan yang baik tentang imunisasi pentavalen booster, 78\% responden menyatakan bahwa pengetahuan di dapat dari tenaga kesehatan $81 \%$ dari responden bersikap mendukung dengan baik.

Berdasarkan survey awal yang dilakukan peneliti data yang 
ada di klinik Sally pada bulan januari-februari tahun 2019 jumlah ibu yang membawa anaknya untuk imunisasi berjumlah 162 orang. Ibu yang membawa anak untuk imunisasi ulangan DPT adalah 10 orang dan yang membawa anak untuk imunisasi ulangan campak adalah 14 orang, dan 138 orang ibu lainnya membawa anaknya untuk imunisasi dasar.

\section{METODE PENELITIAN}

Metode penelitian yang digunakan dalam penelitian ini adalah deskriptif. Pada penelitian ini ingin mengetahui bagaimana gambaran pengetahuan ibu tentang pentingnya pemberian imunisasi booster pada balita di klinik sally tahun 2019.

Penelitian ini dilaksanakan di klinik sally jalan tempulingWaktu penelitian merupakan jadwal yang ditetapkan dan digunakan oleh peneliti dalam melakukan penelitiannya. Penelitian ini dilakukan mulai bulan April sampai dengan bulan Mei tahun 2019 di Klinik Sally. Populasi dalam penelitian ini adalah seluruh ibu yang memiliki anak balita yang datang berkunjung ke klinik sally. Teknik pengambilan sample pada kasus ini adalah Accidental Sampling .

Teknik pengumpulan data yaitu data primer melalui pengisian kuesioner. Dalam penelitian ini peneliti membagikan kuesioner kepada ibu yang memiliki balita yang datang berkunjung ke Klinik Sally, melakukan wawancara langsung untuk mengetahui pengetahuan ibu tentang pentingnya pemberian imunisasi booster pada balita. Dari hasil penelitian dikumpulkan dalam satu tabel kemudian diolah secara manual dengan menggunakan kalkulator lalu disajikan dalam bentuk tabel disertai penjelasan.

\section{HASIL PENELITIAN}

Tabel 1. Distribusi Frekuensi Karakteristik Responden

\begin{tabular}{|c|c|c|c|}
\hline No & Karakteristik & $\begin{array}{l}\text { Frekuensi } \\
\text { (f) }\end{array}$ & $\begin{array}{c}\text { Persent } \\
\text { ase }\end{array}$ \\
\hline \multirow[t]{6}{*}{1.} & Umur & & \\
\hline & $<20$ tahun & 0 & $0,0 \%$ \\
\hline & 20-30 tahun & 24 & 80,0 \\
\hline & $>30$ tahun & 6 & 20,0 \\
\hline & & & $\%$ \\
\hline & Total & $\overline{30}$ & $100 \%$ \\
\hline \multirow[t]{6}{*}{2.} & Pekerjaan & & \\
\hline & Ibu Rumah & 22 & $73,3 \%$ \\
\hline & Tangga & & \\
\hline & Wiras wasta & 8 & $\begin{array}{c}26,7 \\
\%\end{array}$ \\
\hline & PNS & 0 & $0,0 \%$ \\
\hline & Total & 30 & $100 \%$ \\
\hline \multirow[t]{7}{*}{3.} & Pendidikan & & \\
\hline & SD & 0 & $0,0 \%$ \\
\hline & SMP & 5 & $16,7 \%$ \\
\hline & SMA & 19 & $63,3 \%$ \\
\hline & Perguruan & 6 & 20,0 \\
\hline & Tinggi & & \\
\hline & Total & 30 & $100 \%$ \\
\hline \multirow[t]{8}{*}{5.} & Sumber & & \\
\hline & Informasi & & \\
\hline & Koran & 0 & $0,0 \%$ \\
\hline & Media & & 10,0 \\
\hline & Elektronik & 3 & $\%$ \\
\hline & Petugas & 27 & $90,0 \%$ \\
\hline & Kesehatan & & \\
\hline & Total & 30 & $100 \%$ \\
\hline
\end{tabular}

Tabel 5.2.1. menunjukkan bahwa dari 30 responden berdasarkan umur, mayoritas responden berumur 20-30 tahun sebanyak 24 orang $(80,0 \%)$, dan 
yang memiliki umur > 30 tahun sebanyak 6 orang $(20,0 \%) \quad$ Tabel 2 .

Berdasarkan pekerjaan, dari 30 responden sebagian besar ibu memiliki pekerjaan sebagai Ibu Rumah Tangga adalah sebanyak 22 orang $(73,3 \%)$, ibu yang memiliki pekerjaan sebagai wiraswasta sebanyak 8 orang $(26,7 \%)$.

Berdasarkan pendidikan, dari 30 respondenibu yang memiliki pengetahuan berdasarkan pendidikan terakhir SMP sebanyak 5 orang $(16,7 \%)$, pendidikan terakhir SMA sebanyak 19 orang $(63,3 \%)$, dan pendidikan terakhir Perguruan tinggi dengan sebanyak 6 orang (20\%).

Berdasarkan sumber informasi yang didapat, dari 30 responden ibu yang mendapatkan informasi melalui Media Elektronik adalah sebanyak 3 orang $(10,0 \%)$, dan yang mendapatkan sumber informasi melalui Petugas Kesehatan sebanyak 27 orang $(90,0 \%)$.

TabeL 3. Distribusi Frekuensi Gambaran Pengetahuan Ibu Tentang Pentingnya Pemberian Imunisasi Booster Pada Balita BerdasarkanUmur di Klinik Sally tahun 2019.

\begin{tabular}{|c|c|c|c|c|c|c|c|c|c|}
\hline \multirow[t]{3}{*}{ No } & \multirow[t]{3}{*}{ Umur } & \multicolumn{6}{|c|}{ Tingkat Pengetahuan } & \multirow{2}{*}{\multicolumn{2}{|c|}{ Jumlah }} \\
\hline & & \multicolumn{2}{|c|}{ Baik } & \multicolumn{2}{|c|}{ Cukup } & \multicolumn{2}{|c|}{ Kurang } & & \\
\hline & & $\mathbf{F}$ & $\%$ & $\mathbf{f}$ & $\%$ & $\mathbf{F}$ & $\%$ & $\mathbf{F}$ & $\%$ \\
\hline 1 & $<20$ tahun & - & - & - & - & - & - & . & 0 \\
\hline 2 & 20-30 tahun & 7 & 23,3 & 16 & 53,3 & 1 & 3,3 & 24 & 80 \\
\hline \multirow[t]{2}{*}{3} & $>30$ tahun & 1 & 3,3 & 5 & 16,7 & - & - & 6 & 20 \\
\hline & Total & 8 & 26,7 & 21 & 70 & 1 & 3,3 & 30 & 100 \\
\hline $\begin{array}{l}\text { lari } \\
\text { enge } \\
\text { ooste } \\
0-30 \\
\text { eban }\end{array}$ & $\begin{array}{l}\text { Dari tabel } 5 \text {. } \\
30 \text { resp } \\
\text { ahuan ibu te } \\
\text { pada balita } b \\
\text { tahun berpe } \\
\text { ak } 7\end{array}$ & $\begin{array}{l}\text { dal } \\
\text { en } \\
\text { ing }\end{array}$ & $\begin{array}{l}\text { diliha } \\
\text { bahw }\end{array}$ & & \multicolumn{5}{|c|}{$\begin{array}{l}\text { berpengetahuan cukup sebanyak } 16 \\
\text { orang }(53,3 \%) \text {, dan berpengetahuan } \\
\text { kurang yaitu } 1 \text { orang }(3,3 \%) \text {, } \\
\text { berdasarkan umur }>30 \text { tahun yang } \\
\text { berpengetahuan baik } 1 \text { orang }(3,3 \%) \text {, } \\
\text { berpengetahuan cukup } 5 \text { orang } \\
(16,7 \%) \text {. }\end{array}$} \\
\hline
\end{tabular}


Tabel 4. DistribusiFrekuensi Gambaran Pengetahuan Ibu TentangPentingnya Pemberian Imunisasi Booster Pada Balita BerdasarkanPekerjaan di Klinik Sally tahun 2019.

\begin{tabular}{|c|c|c|c|c|c|c|c|c|c|}
\hline \multirow[t]{3}{*}{ No } & \multirow[t]{3}{*}{ Pekerjaan } & \multicolumn{6}{|c|}{ Tingkat Pengetahuan } & \multicolumn{2}{|c|}{ Jumlah } \\
\hline & & \multicolumn{2}{|c|}{ Baik } & \multicolumn{2}{|c|}{ Cukup } & \multicolumn{2}{|c|}{ Kurang } & & \\
\hline & & $\mathbf{f}$ & $\%$ & $\mathbf{f}$ & $\%$ & $\mathbf{F}$ & $\%$ & $\mathbf{F}$ & $\%$ \\
\hline 1 & IRT & 6 & 20 & 15 & 50 & 1 & 3,3 & 22 & 73,3 \\
\hline 2 & Wiras wasta & 2 & 6,7 & 6 & 20 & - & - & 8 & 26,7 \\
\hline 3 & PNS & - & - & - & - & - & - & 0 & 0 \\
\hline & Total & 8 & 26,7 & 21 & 70,0 & 1 & 3,3 & 30 & 100 \\
\hline
\end{tabular}

Dari tabel 5.2.4. dapat dilihat bahwa dari 30 respondenpengetahuan ibu tentang imunisasi booster pada balita berdasarkan pekerjaan yang berpengetahuan baik bekerja sebagai IRT sebanyak 6 orang (20\%), berpengetahuan cukup sebanyak 15 orang (50\%), dan berpengetahuan

Tabel 5.DistribusiFrekuensi Gambaran Pengetahuan Ibu Tentang Pentingnya Pemberian Imunisasi Booster Pada Balita BerdasarkanPendidikan di Klinik Sally tahun 2019.

\begin{tabular}{|c|c|c|c|c|c|c|c|c|c|}
\hline \multirow[t]{3}{*}{ No } & \multirow[t]{3}{*}{ Pendidikan } & \multicolumn{6}{|c|}{ Tingkat Pengetahuan } & \multicolumn{2}{|c|}{ Jumlah } \\
\hline & & \multicolumn{2}{|c|}{ Baik } & \multicolumn{2}{|c|}{ Cukup } & \multicolumn{2}{|c|}{ Kurang } & & \\
\hline & & $\mathbf{f}$ & $\%$ & $\mathbf{f}$ & $\%$ & $\mathbf{F}$ & $\%$ & $\mathbf{F}$ & $\%$ \\
\hline 1 & SD & - & - & - & - & - & - & - & - \\
\hline 2 & SMP & - & _ & 4 & 13,3 & 1 & 3,3 & 5 & 16,7 \\
\hline 3 & SMA & 4 & 13,3 & 15 & 50 & - & - & 19 & 63,3 \\
\hline 4 & $\begin{array}{l}\text { Perguruan } \\
\text { tinggi }\end{array}$ & 4 & 13,3 & 2 & 6,7 & - & - & 6 & 20 \\
\hline & Total & 8 & 26,6 & 21 & 70,0 & 1 & 3,3 & 30 & 100 \\
\hline
\end{tabular}

Dari tabel 5.2.5. dapat dilihat dari 30 responden bahwa pengetahuan ibu tentang imunisasi booster berdasarkan pendidikan terakhir SMPyang memilikipengetahuan cukup adalah 4 orang (13,3\%), memiliki pengetahuan kurang 1 orang $(3,3 \%)$, berdasarkan pendidikan terakhir kurang yaitu 1 orang $(3,3 \%)$, tingkat pengetahuan ibu tentang imunisasi booster pada balita berdasarkan pekerjaan yang berpengetahuan baik bekerja sebagai Wiraswasta sebanyak 2 orang $(6,7 \%)$, dan yang berpengetahuan cukup sebanyak 6 orang $(20 \%)$. 
Tabel 6.DistribusiFrekuensi Gambaran Pengetahuan Ibu Tentang Pentingnya Pemberian Imunisasi Booster Pada Balita BerdasarkanSumber Informasi di Klinik Sally tahun 2019.

\begin{tabular}{|c|c|c|c|c|c|c|c|c|c|}
\hline \multirow[t]{3}{*}{ No } & \multirow{3}{*}{$\begin{array}{l}\text { Sumber } \\
\text { Informasi }\end{array}$} & \multicolumn{6}{|c|}{ Tingkat Pengetahuan } & \multirow{2}{*}{\multicolumn{2}{|c|}{ Jumlah }} \\
\hline & & \multicolumn{2}{|c|}{ Baik } & \multicolumn{2}{|c|}{ Cukup } & \multicolumn{2}{|c|}{ Kurang } & & \\
\hline & & $\mathbf{f}$ & $\%$ & $\mathbf{f}$ & $\%$ & $\mathbf{F}$ & $\%$ & $\mathbf{F}$ & $\%$ \\
\hline 1 & Koran & - & - & - & - & - & - & - & - \\
\hline 2 & $\begin{array}{l}\text { Media } \\
\text { Elektronik }\end{array}$ & - & - & 3 & 10 & - & - & 3 & 10 \\
\hline 3 & $\begin{array}{l}\text { Petugas } \\
\text { Kesehatan }\end{array}$ & 8 & 26,7 & 18 & 60 & 1 & 3,3 & 27 & 90 \\
\hline
\end{tabular}

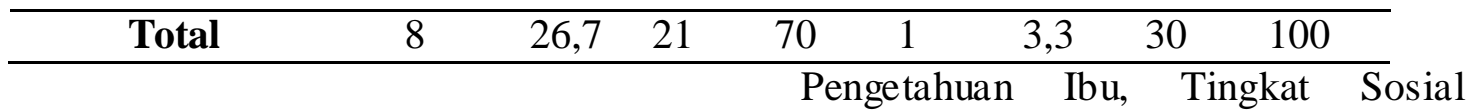

Dari tabel 5.2.6 dapat dilihat dari 30 responden bahwa pengetahuan ibu tentang imunisasi booster berdasarkan sumber informasi media elektronik yang berpengetahuan cukup sebanyak 3 orang $(10 \%)$, dan tingkat pengetahuan ibu tentang imunisasi booster berdasarkan sumber informasi dari petugas kesehatan yang berpengetahuan baik sebanyak 8 orang (26,7\%), berpengetahuan cukup sebanyak 18 orang $(60 \%)$, dan yang berpengetahuan kurang yaitu 1 orang $(3,3 \%)$.

\section{PEMBAHASAN}

\section{Pengetahuan Ibu Tentang Imunisasi Booster Pada Balita}

Hasil penelitian dari 30 responden bahwa mayoritas responden yang memiliki pengetahuan baik adalah 8 orang $(26,7 \%)$, berpengetahuan cukup 21 orang $(70,0 \%)$, dan yang berpengetahuan kurang ada 1 orang $(3,3 \%)$. Maka dapat disimpulkan bahwa pengetahuan ibu berpengetahuan cukup.

Hasil penelitian ini sejalan dengan penelitian yang dilakukan oleh saudari Delan (2011) yang berjudul "Hubungan Antara Tingkat
Ekonomi Dengan Status Imunisasi Dasar Lengkap Pada Balita". Pada penelitian ini didapatkan hasil bahwa dari 50 responden yang memiliki pengetahuan cukup sebanyak 24 orang (48\%), yang memiliki pengetahuan kurang berjumlah 18 orang (36\%), dan yang memiliki pengetahuan baik adalah 8 orang (16\%). Sehingga disimpulkan mayoritas responden berpengetahuan cukup.

Penelitian sebelumnya yang dilakukan oleh Puspitaningrum yang berjudul "Hubungan Tingkat Pengetahuan Dengan Kepatuhan Ibu Dalam Pemberian Imunisasi Pentavalen Di wilayah Kerja UPTD Puskesmas Gilingan Surakarta" juga menunjukkan bahwa dari 56 jumlah responden yang memiliki pengetahuan cukup sebanyak 33 orang $(58,9 \%)$.

Pengetahuan adalah merupakan hasil mengingat suatu hal, termasukmengingat kembali kejadian yang pernah dialami baik secara sengaja maupun tidaksengaja dan ini terjadi setelah orang melakukan kontak atau pengamatan terhadapsuatu obyek tertentu (Mubarok, 2011).

Menurut teori Pengetahuan adalah merupakan hasil "tahu" dan ini terjadi setelah orang melakukan 
penginderaan terhadap suatu objek tertentu. Penginderaan ini terjadi melalui panca indra manusia. Pengetahuan atau kognitif merupakan domain yang sangat penting bagi terbentuknya tindakan seseorang. Perilaku yang didasari oleh pengetahuan akan lebih langgeng daripada perilaku yang tidak didasari oleh pengetahuan (Nursalam, 2012).

Menurut asumsi peneliti, bahwa tingkat pengetahuan responden mayoritas berpengetahuan cukup, hal ini menunjukkan bahwa ibu masih berpengetahuan cukup tentang pentingnya pemberian imunisasi booster pada balita.

\section{Pengetahuan Ibu Tentang Pentingnya pemberian Imunisasi Booster Pada Balita Berdasarkan Umur}

Berdasarkan hasil penelitian yang diperoleh bahwa pengetahuan ibu tentang pentingnya pemberian imunisasi booster pada balita berdasarkan umur yang berpengetahuan baik terdapat pada usia 26-35 tahun sebanyak 8 orang $(26,7 \%)$, berpengetahuan cukup sebanyak 21 orang $(70 \%)$, berpengetahuan kurang sebanyak 1 orang $(3,3 \%)$. Maka dapat disimpulkan umur ibu pa usia 26-35 tahun berpengetahuan cukup.

Hal ini sejalan dengan penelitian Nurazizah (2012) yang menyatakan bahwa umur merupakan salah satu faktor yang berpengaruh terhadap pengetahuan seseorang, sebagian orang yang umurnnya masih muda memiliki minat untuk belajar lebih banyak dibandingkan dengan orang yang usianya sudah tua. Dimana minat merupakan suatu rasa ketertarikan pada suatu hal atau aktivitas. Selain itu, orang tua diusia 20-an cukup perhatian dalam hal kesehatan dan mempunyai kesadaran yang tinggi untuk menerapkan program kesehatan yang bersifat prevenif kepada anak-anaknya.

Umur adalah usia individu yang terhitung mulai saat dilahirkan sampai saat beberapa tahun. Semakin cukup umur, tingkat kematangan seseorang akan lebih matang dalam berfikir dan bekerja. Usia mempengaruhi terhadap daya tangkap dan pola pikir seseorang. Semakin bertambah usia akan semakin berkembang pula daya tangkap dan pola pikirnya, sehingga pengetahuan yang diperolehnya semakin membaik( Budiman, 2013 ).

Usia mempengaruhi daya tangkap dan pola pikir seseorang. Bertambahnya usia akan semakin berkembang pola pikir dan daya tangkap seseorang sehingga pengetahuan yang diperoleh akan semakin banyak (Fitriani 2015).

Menurut asumsi peneliti, bahwa semakin banyak usia tidak menjamin akan semakin baik pula tingkat pengetahuan seseorang. Karena hasil penelitaian yang didapat bahwa tingkat pengetahuan responden berdasarkan umur 26-35 tahun mayoritas berpengetahuan cukup, hal ini menunjukkan bahwa responden dengan umur 26-35 tahun sudah cukup tau tentang pentingnya pemberian imunisasi booster pada balita, karena kisaran umur 26-35 tahun merupakan usia reproduksi dimana pada saat ini semakin cukup umur, tingkat kematangan dan kekuatan seseorang akan lebih matang dalam berfikir dan bekerja.

\section{Pengetahuan Ibu Tentang Pentingnya Pemberian Imunisasi}




\section{Booster Pada Balita Berdasarkan Pekerjaan}

Berdasarkan hasil penelitian diperoleh bahwa pengetahuan ibu tentang pentingnya pemberian imunisasi booster pada balita berdasarkan Pekerjaan yang berpengetahuan baik terdapat pada ibu yang bekerja sebagai Ibu Rumah Tangga sebanyak 6 orang (20\%), berpengetahuan cukup 15 orang (50\%), berpengetahuan kurang 1 orang $(3,3 \%)$, dan ibu yang bekerja sebagai Wiraswasta berpengetahuan baik sebanyak 2 orang $(6,7 \%)$, berpengetahuan cukup sebanyak 6 orang $(20 \%)$. Maka dapat disimpulkan ibu yang bekerja sebagai rumah tangga berpengetahuan cukup dan ibu yang bekerja diluar rumah berpengetahuan baik.

Hal ini sejalan dengan dengan penelitian yang dilakukan oleh Palupi (2012) bahwa responden yang bekerja di luar rumah cenderung memiliki tingkat pengetahuan yang lebih baik dibanding yang tidak bekerja.

Menurut hasil penelitian sebelumnya yang dilakukan oleh saudari Nurazizah (2012) menunjukkan bahwa pekerjaan responden adalah pada Ibu Rumah Tangga (IRT) sebanyak 75 responden (57\%), Wiraswasta sebanyak 25 responden (18 $\%$ ), dan PNS sebanyak 35 responden (25 \%).Semua ini disebabkan karena ibu yang bekerja di luar rumah (sektor formal) memiliki akses yang lebih baik terhadap berbagai informasi, termasuk mendapatkan informasi tentang pemberian Imunisasi Booster pada anak.

Menurut asumsi peneliti bahwa pekerjaan ibu dapat mempengaruhi pengetahuan ibu terutama tentang imunisasi booster sebab ibu yang bekerja di luar rumah memiliki akses yang lebih mudah untuk mendapatkan informasi tentang imunisasi booster baik itu dari petugas kesehatan maupun teman dalam bekerja.

\section{PengetahuanIbuTentang}

Pentingnya Pembe rian Imunisasi Booster Pada Balita Berdasarkan Pendidikan.

Berdasarkan hasil penelitian yang didapat bahwa pengetahuan ibu tentang pentingnya pemberian imunisasi booster pada balita berdasarkan pendidikan terakhir Perguruan tinggi berpengetahuan baik sebanyak 4 orang $(13,3 \%)$, berpengetahuan cukup 2 orang $(6,7 \%)$, dan yang berpendidikan terakhir SMA berpengetahuan cukup sebanyak 15 orang (50\%). Maka di simpulkan ibu yang berpendidikan perguruan tinggi berpengetahuan baik, sedangkan ibu yang berpendidikan SMA berpengetahuan cukup.

Hal ini sejalan dengan penelitian Albertina (2009) yang menyimpulkan bahwa semakin tinggi tingkat pendidikan seorang ibu maka makin besar peluang untuk mengimunisasikan bayinya.

Menurut teori (Fitriani 2015), yang menyatakan Pendidikan adalah suatu usaha untuk mengembangkan keperibadian dan kemampuan di dalam dan di luar sekolah yang berlangsung seumur hidup. Pendidikan mempengaruhi proses belajar, semakin tinggi pendidikan seseorang maka semakin mudah orang tersebut untuk menerima informasi. Pendidikan tinggi seseorang akan mendapatkan informasi baik dari orang lain maupun media massa. Semakin banyak informasi yang masuk, semakin banyak pula 
pengetahuan yang didapat tentang kesehatan.

Menurut asumsi peneliti bahwa pendidikan sangat mempengaruhi tingkat pengetahuan seseorang, karena semakin tinggi pendidikan maka semakin luas dan mudah pula dalam menerima informasi, ide-ide dari orang lain.

\section{.5. Pengetahuan Ibu Tentang Pentingnya Pemberian Imunisasi Booster Pada Balita Berdasarkan Sumber Informasi.}

Berdasarkan hasil penelitian pengetahuan ibu tentang pentingnya pemberian imunisasi booster pada balita berdasarkan sumber informasi yang didapat dari media elektronik memiliki pengetahuan cukup sebanyak 3 orang (10\%), berdasarkan sumber informasi yang didapat dari petugas kesehatan memiliki pengetahuan yang baik sebanyak 8 orang $(26,7 \%)$, berpengetahuan cukup sebanyak 18 orang (60\%), dan yang berpengetahuan kurang yaitu 1 orang $(3,3 \%)$.

Informasi yang diperoleh baik dari pendidikan formal maupun non formal dapat memberikan pengetahuan jangka pendek (immediate 10 impact), sehingga menghasilkan perubahan dan peningkatan pengetahuan. Kemajuan teknologi menyediakan bermacammacam media massa yang dapat mempengaruhi pengetahuan masyarakat tentang informasi baru. Sarana komunikasi seperti televisi, radio, surat kabar, majalah, penyuluhan, dan lain- lain mempunyai pengaruh besar terhadap pembentukan opini dan kepercayaan orang (fitriani 2015).

Hal ini berbanding terbalik dengan penelitian Astriani (2016), yang menunjukkan bahwa tingkat kelengkapan imunisasi lanjutan pada anak usia dibawah tiga tahun di Puskesmas Denpasar Selatan memiliki hubungan bermakna dengan peran tenaga kesehatan.

Menurut asumsi peneliti pengetahuan ibu tentang imunisasi booster berdasarkan sumber informasi yang didapat dari petugas kesehatan sudah cukup, namun disebabkan oleh kurangnya kesadaran ibu untuk mencari tahu akan pentingnya anak diberikan imunisasi Booster untuk menghindari penyakit. Tidak hanya melalui Petugas Kesehatan, ibu bisa saja mendapatkan informasi tentang imunisasi booster dari berbagai media cetak ataupun media elek tronik karena canggihnya perkembangan zaman membawa dampak yang sangat besar terhadap pengetahuan ibu dimana ibu sudah lebih cenderung menggunakan gadget sebagai alat untuk mencari sumber informasi

\section{KESIMPULAN}

Dari hasil penelitian yang telah dilakukan terhadap ibu tentang pentingnya pemberian imunisasi booster pada balita di Klinik Sally tahun 2019 dan pengolahan data yang dilakukan, dapat diambil kesimpulan sebagai berikut

1. Berdasarkan hasil penelitian, bahwa pengetahuan ibu tentang pentingnya pemberian imunisasi booster pada balita di Klinik Sally tahun 2019 masuk dalam kategori cukup. Hal ini dikarenakan beberapa faktor yaitu usia, pendidikan, pekerjaan dan sumber informasi yang diterima oleh responden, juga persepsi orang tua yang salah tentang imunisasi sehingga dapat meyakinkan ibu 
bahwa pemberian imunisasi tidak menimbulkan masalah kesehatan pada anak.

2. Berdasarkan hasil penelitian, bahwa tingkat pengetahuan ibu tentang pentingnya pemberian imunisasi booster pada balita di Klinik Sally tahun 2019 berdasarkan umur responden mayoritas pada umur 2635 tahun yaitu yang memiliki pengetahuan baik sebanyak 7 orang $(2,3 \%)$, dan yang memiliki pengetahuan cukup adalah sebanyak 16 orang $(53,3)$. Hal ini dikarenakan semakin bertambah usia akan semakin berkembang pula daya tangkap dan pola pikirnya, sehingga pengetahuan yang diperolehnya semakin banyak ( Budiman, 2013 ).

3. Berdasarkan hasil penelitian, bahwa tingkat pengetahuan ibu tentang pentingnya pemberian imunisasi booster pada balita di Klinik Sally tahun 2019 berdasarkan Pekerjaan responden mayoritas bekerja sebagai Ibu Rumah Tangga memiliki pengetahuan cukup. Semua ini disebabkan karena ibu yang bekerja di luar rumah memiliki akses yang lebih baik terhadap berbagai informasi, termasuk mendapatkan informasi tentang pemberian Imunisasi Booster pada anak.

4. Berdasarkan hasil penelitian, bahwa tingkat pengetahuan ibu tentang pentingnya pemberian imunisasi booster pada balita di Klinik Sally tahun 2019 berdasarkan pendidikan terakhir mayoritas responden memiliki pengetahuan yang cukup pada pendidikan terakhir SMA. Hal ini sesuai dengan teori (Fitriani 2015), pendidikan mempengaruhi proses belajar semakin tinggi pendidikan seorang maka semakin mudah untuk menerima informasi dan pengetahuannya juga akan semakin baik didukung oleh pendidikannya tersebut.

5. Berdasarkan hasil penelitian, bahwa tingkat pengetahuan ibu tentang pentingnya pemberian imunisasi booster pada balita di Klinik Sally tahun 2019 berdasarkan sumber informasi dari petugas kesehatan mayoritas memiliki pengetahuan cukup. Hal ini dikarenakan kurangnya kesadaran ibu mencari tau pentingnya imunisasi booster pada anak yang juga dapat diperoleh dari berbagai media elektronik maupun media cetak, semakin banyak informasi yang masuk semakin banyak pula pengetahuan yang didapat tentang imunisasi booster pada anak.

\section{SARAN}

Bagi institusi, Sebagai tambahan refernsi dan informasi dalam bidang pendidikan kesehatan, serta dapat dijadikan tambahan ke perpustakaan dalam pengembangan penelitian selanjutnya.

Bagi responden, asil penelitian ini dapat memberikan informasi kepada responden tentang pentingnya pemberian imunisasi booster pada balita, untuk meningkatkan kembali respon imun anak terhadap vaksin yang sudah menurun seiring dengan bertambahnya usia anak. Diharapkan juga kepada ibu agar kiranya meluangkan waktu untuk menghadiri kegiatan-kegiatan yang bermanfaat seperti penyuluhan tentang pentingya kesehatan terutama imunisasi booster pada anak.

Bagi petugas kesehatan, diharapkan penelitian ini memberikan masukan bagi Petugas Kesehatan untuk lebih memperluas cakupan penyuluhan 
dan memberi informasi kepada ibu untuk lebih mengetahui tentang Imunisasi booster, Tenaga kesehatan harus dapat membantu memberikan pemahaman kepada orang tua dan membantu mengubah persepsi orang tua yang salah tentang imunisasi sehingga dapat meyakinkan ibu bahwa pemberian imunisasi tidak menimbulkan masalah kesehatan pada anak.

Bagi peneliti, hasil penelitian ini semoga dapat menambah wawasan baru dan ilmu pengetahuan, khususnya dalam bidang ilmu kebidanan. Serta pengalaman pertama yang sangat berharga dalam melaksanakan penelitian demi penelitian selanjutnya.

\section{DAFTAR PUSTAKA}

Ali, M. (2003). Pengetahuan, Sikap dan Perilaku Ibu Bekerja dan Ibu Tidak Bekerja Tentang Imunisasi.

Arsita, N. (2017). Implementasi Peraturan Menteri Kesehatan Nomor 42 Tahun 2013 Tentang Penyelenggaraan Imunisasi (Studi kasus pada Puskesmas Banguntapan II Kabupaten Bantul).

Asrtianzah, D., \& Margawati, A. (2011). Hubungan Antara Tingkat Pengetahuan Ibu, Tingkat Sosial Ekonomi dengan Status Imunisasi Dasar Lengkap pada Balita.

Atikah Proverawati, S. M. (2017). Imunisasi dan Vaksin. Yogyakarta: Nuha Medika.
Budiman, R, T(2013). Kapita Selekta Kuesioner Pengetahuan dan sikap dalam penelitian Kesehatan. Jakarta : Salemba Medika. Diakses pada tanggal 02 Februari 2019.

Creswell, Jhon. (2009). Research design Qualitative, Quantitative And Mixed Metods Approaches Third Edition.American: Sage

Daryanto. (2017). Faktor Penghambat Pemahaman. Surabaya: Suka Maju.

Donsu, J, D, T. (2016). Metodologi Penelitian Keperawatan. Yogyakarta : Pustaka Baru Press. Cetakan I.

Dwi Maryanti, S. d. (2011). Buku Ajar Neonatus, Bayi \& Balita. Jakarta: CV. Trans Info Media.

Ermawati, D. H., Cahyanto, E. B., \& Musfiroh, M. (2018). Pengaruh Penyuluhan Terhadap Pengetahuan Ibu Tentang Imunisasi Pentavalen Lanjutan Pada Batita Di Kelurahan Keprabon Surakarta. Jurnal EDUMidwifery, 1(2), 68-78.

Fitriani N, T(2015), Sikap dalam Penelitian Kesehatan. Jakarta : Salemba

Grove, susan. (2015). Understanding Nursing Research Building An Evidence Based Practice, 6 th Edition. China Elseiviar

Husada, S. K. Hubungan Tingkat Pengetahuan Dengan Kepatuhan Ibu Dalam 
Pemberian Imunisasi

Pentavalen Di Wilayah Kerja

Uptd Puskesmas Gilingan Surakarta.

Itsa, N. S. (2019). Faktor-Faktor Yang Berhubungan Dengan Status Imunisasi Lanjutan Pentavalen (Dpt-Hb-Hib) Di Wilayah Kerja Puskesmas Labuhan Ratu Kota Bandar Lampung Tahun 2018.

Kementerian Kesehatan, R. I. (2015). Profil kesehatan indonesia. Jakarta: Kementerian Kesehatan RI.

Kementrian Kesehatan, R. I. (2016). Profil kesehatan Indonesia tahun 2016. Jakarta: Kementerian Kesehatan Republik Indonesia.

Kesehatan, K., \& Kesehatan, K. (2017). Data dan Informasi Profil Kesehatan Indonesia 2016.

Lilis Lisnawati, S. M. (2016). Generasi Sehat Melalui Imunisasi. Jakarta: CV. Trans Info Media.

Marimbi, H. (2017). Tumbuh Kembang, Status Gizi, dan Imunisasi Dasar Pada Balita. Yogyakarta: Nuha Medika.

Medan, P. K. (2016). Angka Kematian Balita Per 1.000 Kelahiran Hidup. Angka Kematian Balita Per 1.000 Kelahiran Hidup , hal. 21.

Menteri Kesehatan, R. I. (2017). Peraturan Menteri Kesehatan
Republik Indonesia Nomor 12

Tahun $2017 \quad$ tentang

Penyelenggaraan Imunisasi.

Kementeri Kesehat, 1-162.

Mubarok, T (2011). Promosi Kesehatan. Yogyakarta : Graha Ilmu

Munawaroh, A., Syamsulhuda, S. B., \& Widjanarko, B. (2016). Beberapa faktor yang berhubungan dengan praktik imunisasi pentavalen booster di Wilayah Kerja Puskesmas Mangunsari Salatiga. Jurnal Kesehatan Masyarakat (eJournal), 4(3), 949-959.

Noviasty, R., Handayani, I. D., \& Alawiah, W. (2018). Pekerjaan Ibuku Mempengaruhi Kelengkapan Imunisasiku. Jurnal Ilmu Kesehatan Vol, 7(1).

Nurazisah, N. (2012). Gambaran Pengetahuan Ibu Tentang Imunisasi Booster pada Anak di Kota Makassar Tahun 2012.

Nursalam. 2014. Metodologi Penelitian Ilmu Keperawatan: Pendekatan Praktis Edisi 3. Jakarta : Salemba Medika

Nursalam. 2015. Metodologi Penelitian Ilmu Keperawatan. Jakarta : Salemba Medika

Nursalam. 2016. Metodologi Penelitian Ilmu Keperawatan. Jakarta : Salemba Medika

Polit, Denise F \& Cheryl Tatano Beck. (2012). Nursing Reserchhing : Generating And Assessing Evidence For 
Nursing Practice ( 9 Th Ed.). Philadephina : Lippincott Williams \&Wilkinis.

Pujiasih, K., \& Sulistyoningtyas, S. (2017). Hubungan Status Pekerjaan Ibu Dengan Ketepatan Waktu Pemberian Imunisasi Pentavalen Dan Campak Lanjutan Pada Batita Di Puskesmas Paliyan.

Purnama, Y., Fadlyana, E., \& Sekarwana, N. (2016). Pengaruh Pengetahuan Terhadap Sikap Ibu Mengenai Imunisasi Ulangan DifteriaTetanus. Sari Pediatri, 10(2), 117-121.

Rahma, F. P., Suryoputro, A., \& Fatmasari, E. Y. (2019). Analisis Pelaksanaan Program Imunisasi DPT-HB-Hib Pentavalen Booster pada Baduta di Puskesmas Kota Semarang (Studi Kasus pada Puskesmas Halmahera). Jurnal Kesehatan Masyarakat (e-Journal), 7(1), 48-56.

Wawan, A. Dewi (2018). Pengetahuan, Sikap dan Perilaku Manusia.Yogyakarta :Nuha Medika

Yunizar, Y., Asriwati, A., \& Hadi, A. J. (2018). Perilaku Ibu dalam Pemberian Imunisasi DPT/HbHib di Desa Sinabang Kecamatan Simeulue Timur. Jurnal Kesehatan Global, 1(2), 61-69. 